\title{
Combustion Visualization of Partially Premixed and Non Premixed Diesel Fuel on Single Cylinder Optical Engine
}

\author{
Cengizhan Cengiz, Aydın Ayyıldız, Serenat Karagöz, Arda Çoşkun, Seyfullah Berk \\ Ford Otosan AŞ., Türkiye \\ C. Cengiz (0000-0003-0992-9855), A. Ayyıldız (0000-0002-8131-0232), A. Coşkun (0000-0002-9052-4523), S. Karagöz (0000-0003-3201-4979)
}

\begin{abstract}
Ignition and flame propagation phenomenon of diesel fuel combustion was investigated in an optical single cylinder engine. Conventional non-premixed diesel combustion and partially premixed combustion types were investigated. Experiments were performed on an optical single cylinder, heavy duty, four-stroke compression ignition engine with a quartz elongated piston bowl and $45^{\circ}$ mirror was used for visualization as a measurement technique. . Self-ignition, flame propagation, heat rejection and effects on number of pilot injections on combustion visualization are investigated. In conventional diesel with closed and far pilot and partially premixed charge compression ignition (PCCI) tests were performed.
\end{abstract}

Keywords: Combustion, PCCI, Optic engine, Flame propagation, Single cylinder

\section{INTRODUCTION}

Diesel engines are the main stream in the heavy duty applications today and this will continue to be a main stream on the future applications considering high thermal efficiency of compression ignition combustion. Current and possible future emission regulations of commercial heavy duty vehicles are mainly focused on $\mathrm{NO}_{x}$ and soot emissions which become more restricted with latest EU6 regulations and future emission regulations will even be more restrictor. Although having after-treatment systems, capable to reduce the $\mathrm{NO}_{x}$ emissions up to $99 \%$, thanks to modern SCR technology, and soot emissions up to $\% 99$ with diesel particulate filters, helps to deal with the regulations, due to component cost, package and the demand of urea dosing to convert NOx emissions exhaust aftertreatment system cost significantly increased in the recent years and become comparable to even base engine cost. In addition, high fuel prices and environmental effects, efficient engines are required to survive for the industry considering the threat of electrification. It is critical to understand the combustion behavior of conventional diesel combustion and alternative ways both to design efficient engines and correlation activities of 3D combustion simulations.

In diesel engines, due to the characteristics of the non-premixed region, combustion takes place both on the fuel rich, low temperature zone which causes soot emissions; and the diffusion controlled zone producing NOx emissions as shown in Figure 1. In this study both conventional non-premixed and partially premixed charged diesel combustion (PCCI) visualizations are investigated in terms of flame propagation and heat rejection.[1]

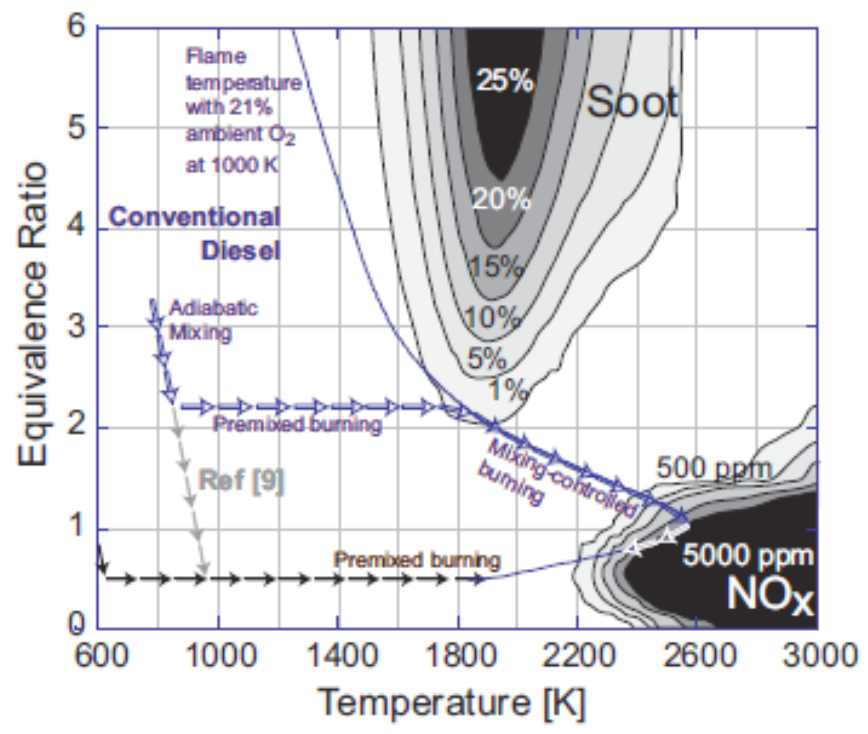

Figure 1: Depiction of conventional and two variants of low temperature combustion on the ER-T plane.[2]

Optical single cylinder engines are key devices to visualize the combustion process of different combustion modes, injection properties, air to fuel mixing quality, spatial distri-
${ }^{*}$ Corresponding authour

Email: ccengiz@ford.com
European Mechanical Science, March 2019; 3(1): 24-31 doi: https://doi.org/10.26701/ems.385475

Received: January 29, 2018

Accepted: November 27, 2018 
bution of NOx, soot emissions, ignition delay and knocking properties. [3] [4] The engine is mentioned in this study is an modified single engine. Additional parts as elongated piston and window cassettes are integrated to the engine.

In this study, section 2 describes the of optical single operating and measurement techniques. In section 3 , conventional and alternative combustion paths of diesel combustion visualization are results shown and discussed about the findings.

\section{EXPERIMENT}

\subsection{Optical Diesel Engine}

Optical single cylinder engine used in study is designed and manufactured by Ford Otosan. It is a four-valve, four stroke diesel engine, based on Ecotorq 13lt Heavy Duty Commercial Engine. Engine head, liner and injection system are carried over from this engine. During measurements, engine is driven by dynamometer and fuel is injected on the motored engine. All auxiliary systems such as fuel, cooling and lubrication except valve train are driven by external systems. The specifications of optical engine data are described in Table 1 below.

\begin{tabular}{|c|c|}
\hline \multicolumn{1}{|c|}{ Table 1 Specification of the engine } \\
\hline Models & Size $(\mathbf{n m})$ \\
\hline Bore $x$ stroke $[\mathrm{mm}]$ & $130 \times 160$ \\
\hline Connecting rod [mm] & 310 \\
\hline Compression ratio & $13: 1$ \\
\hline Squish [mm] & 1.2 \\
\hline Displacement [lt] & 2.1 \\
\hline Swirl ratio & 1.2 \\
\hline Number of valves & 4 \\
\hline Intake valve closing & 140 degCA BTDC \\
\hline
\end{tabular}

Upper side of the engine has window cassette system that has an access to visualize swirl and tumble measurement via PIV system. At the middle section of the engine an elongated piston is positioned. Combustion chamber part of the piston is made of quartz glass. Figure 2 shows the section view and full visualization of the engine. Light emitted from combustion chamber is exited through the quartz piston and reaches the mirror which is positioned on the middle of the elongated piston. Light reflected through the $45^{\circ} \mathrm{mir}-$ ror is received by a high speed camera. Visible area of the combustion chamber is limited with the quartz piston area within the radius of $92 \mathrm{~mm}$ shown in Figure 3.

Compression ratio of the engine is 13:1 which is lower than thermodynamic engine. It is due to maximum cylinder pressure of the engine is limitation of $110 \mathrm{bar}$. This limit is related with the quartz glass durability.

Moreover, combustion heat causes thermal gradient for quartz piston resulting another limiting factor. For this reason, engine is running only for 12 cycles in order to protect the engine from the excessive heat. Transparent piston bowl shape is a bit different from the thermodynamic engine in order to avoid optical distortions. In order to eliminate the optical distortions, a curvature shape is designed for the bottom piston surface. Therefore, distorted image in the curvature top curvature is compensated on the bottom surface. . In many applications, very smooth/simplified or flat surfaced piston bowl shapes are used in the experiments. [5] In this study, a curved bottom surface is used to reduce the optic distortions and thermodynamic engine similar piston is used in order to replicate the combustion behavior as much as possible.

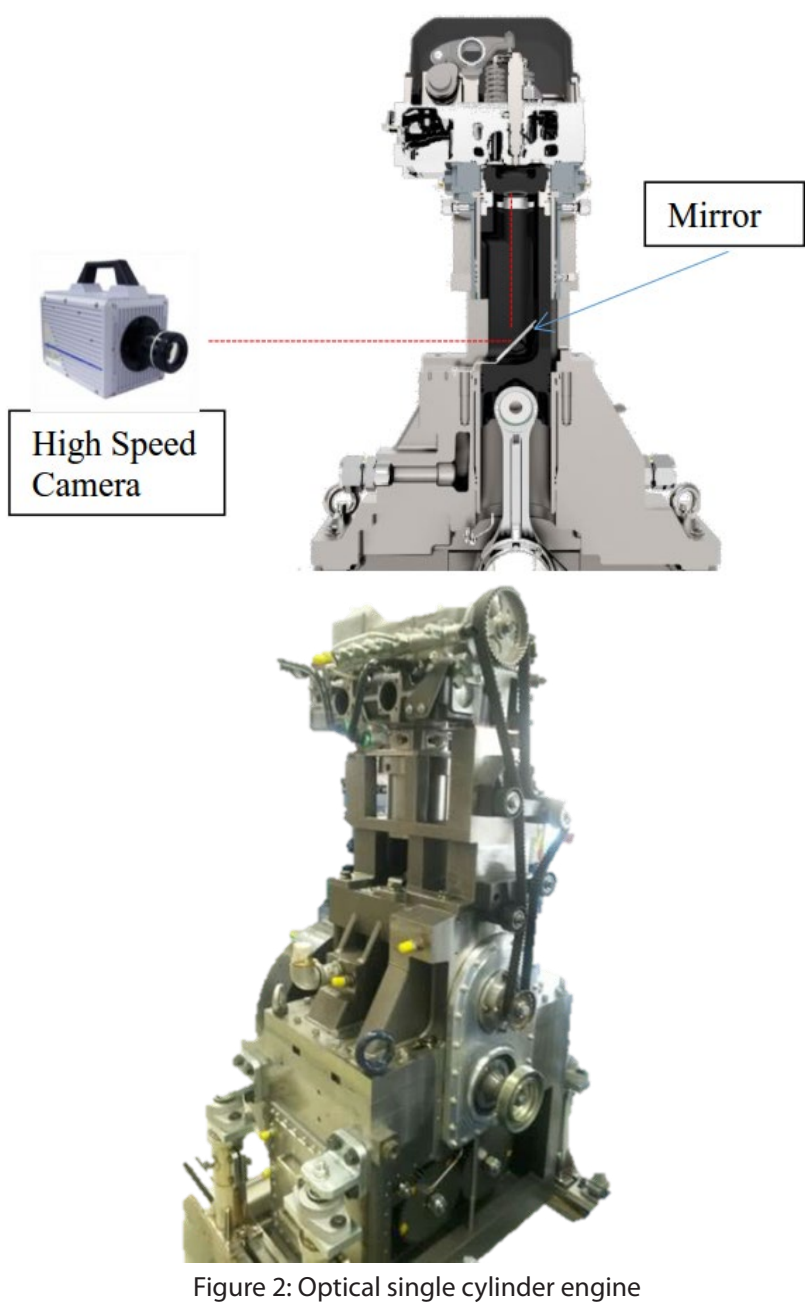

In addition, many optic engine operations, skip-fire technique is used to decrease the thermal load and heating up the glass elements in the engine. Skip-fire technique, fuel injected for a couple cycle and then fule-cuts of in order to cool down the surface periodically. On the other hand, transient behavior of this technique can change the residual gas fraction of the engine. In this work, continuous firing is used to simulate steady state regime and number of total fired cycles is limited.[6]

Fuel injection system is carried out from the commercial heavy duty engine. Fuel pump is driven by an electrical pump externally with a maximum rail pressure capability of 2500 bar. Common-rail systems with solenoid actuated injectors are used in the measurements. Injector fuel flow rate is 850cc/30sec@100bar. A 8 nozzles injector with a 0.180 mm nozzle diameter and $150^{\circ}$ spray angle injector is used. 

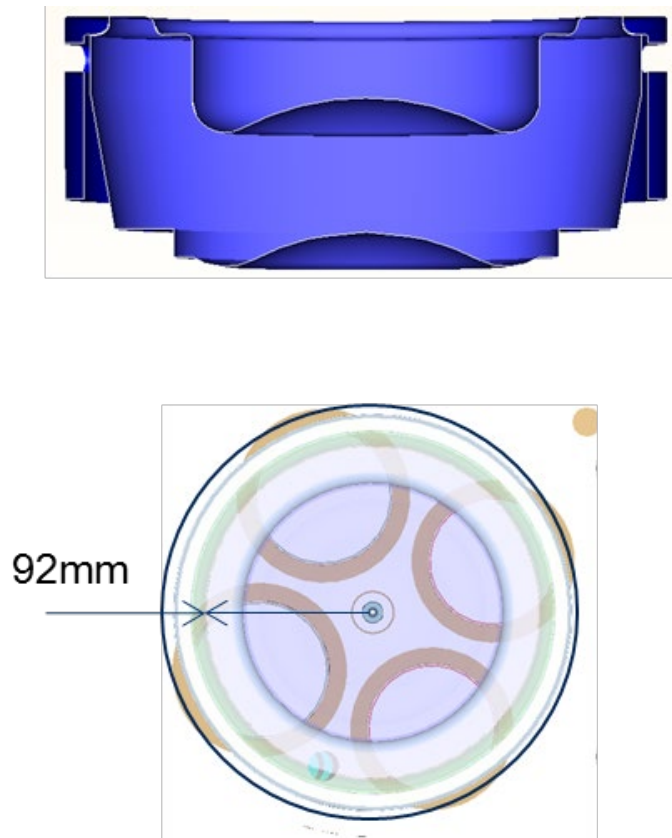

Figure 3: Piston bowl and visible are of the combustion chamber

\subsection{High Speed Camera Measurements}

Combustion images are recorded by high speed camera system. Most of the applications, lasers are used to as a light source for visualization. In this work, combustion itself is used as a light source. A high speed RGB camera (Photron SA5) with a frame rate of $40.000 \mathrm{fps}$ is used to obtain images with a 320 x 256 resolution. System is equipped with a 70 $\mathrm{mm}$ focal length of $\mathrm{f} 4.0$ lens. A parallel signal line from the fuel injector current is used for triggering high speed image capturing.

\subsection{Engine Operation \& Measurement Systems}

For indicating data acquisition, an AVL Indicom in cylinder pressure measurement system with non-cooled piezoelectric pressure sensor is used. In cylinder pressure data is recorded simultaneously and pressure values are averaged of the combustion cycles of 12 cycles. Pressure data is recorded with 0.5 crank angle sampling rate.

During the measurements, engine is conditioned approximately 3-4 hours before starting the engine. Engine coolant and oil temperatures are set to $80^{\circ} \mathrm{C}$. Then, engine is motored to reach the intake manifold pressure set point. It takes about $\sim 60$ secs to reach the flow regime. Boost temperature is controlled via both heat exchangers and electrical heater. In the heating period in advance of motoring, engine is positioned to the valve overlap to make an air flow circulation passing from intake valve to the engine and then exits form exhaust ports to heat-up the combustion chamber of the engine, ports and intake surge tanks.

Boost pressure is controlled via controlled pneumatic valve which connected to the compressed air line.

Operating conditions, effective compression ratio of the engine are summarized at Table 2 .
Table 2 Operating Parameters

\begin{tabular}{|c|c|c|}
\hline Models & $\begin{array}{c}\text { Intake Manifold } \\
\text { Pressure }\end{array}$ & $\begin{array}{c}\text { In cylinder Pressure } \\
\text { @TDC }\end{array}$ \\
\hline Pressure $[$ bar $]$ abs. & 1.6 & 30 \\
\hline Temperature $\left[{ }^{\circ} \mathrm{C}\right]$ & 90 & \\
\hline
\end{tabular}

An automatic operation algorithm is used in the measurements. Dynamometer control system (AVL Puma) is responsible for the all the operations of the single stage measurements. In the first step, after starting the engine dyno controller stabilizes the engine at given speed set point. Then, boost pressure starts to increase up to pre-set value. Once the in-cylinder TDC pressure of the motoring engine reaches the target value, fuel injection starts. At this stage, simultaneously high speed camera starts to capture the images. After 12 cycles, fuel injection cuts off and engine costs down.

\section{RESULTS}

\subsection{Non premixed Combustion with Diesel Fuel}

In this section, non-premixed compression ignited diesel fuel visualization results are discussed. In-cylinder pressure, injection signals are measured, heat release rate is calculated. A pilot injection is used to illuminate and heat up the combustion chamber to able to see the main injection of the spray initiation and flame-lift-off length. Operating conditions are shown in Figure 3 below.

Table 3 Engine Operation on Diesel Cycle

\begin{tabular}{|c|c|}
\hline Models & $\begin{array}{c}\text { Intake Manifold } \\
\text { Pressure }\end{array}$ \\
\hline Engine Speed [rpm] & 1100 \\
\hline Injected Fuel [mg/stroke] & 30 \\
\hline Pilot injection ratio [\%] & 50 \\
\hline Rail pressure [bar] & 800 \\
\hline
\end{tabular}

At this operation point, a pilot injection is performed at 11 deg crank angle (CA) before top dead center (BTDC) and a main injection is started at $2 \mathrm{deg}$. CA after top dead center (ATDC) in Figure 4. In the measurement, pilot injection starts to ignite at $7 \mathrm{deg}$. CA BTDC and main injection starts to ignite 6 deg. CA ATDC.

Figure 5 shows the whole combustion imaging of the engine cycle. Duration between pilot and main injection is very low that main injection occurs before the pilot injection combustion. As a result, main injection spray pattern and flamelift-off length cannot be seen. In the pilot injection combustion, flame starts to propagate near the injection center and simultaneously occurs in the same manner for all injected nozzles. Swirl effect on the combustion can also be observed that, flame also propagates on the swirl center up to $45^{\circ}$ on the clockwise direction.

In the second phase, in order to visualize the spray pattern of the main injection, two piloted injection strategy is performed. In this strategy, first pilot is injected at 10degCA BTDC, a second pilot is injected at $3 \operatorname{degCA}$ BTDC and a far main injection is performed at $11 \mathrm{degCA}$ ATDC. As it is seen in the Figure 6, first ignition initiates at $7 \operatorname{deg} C A$ 


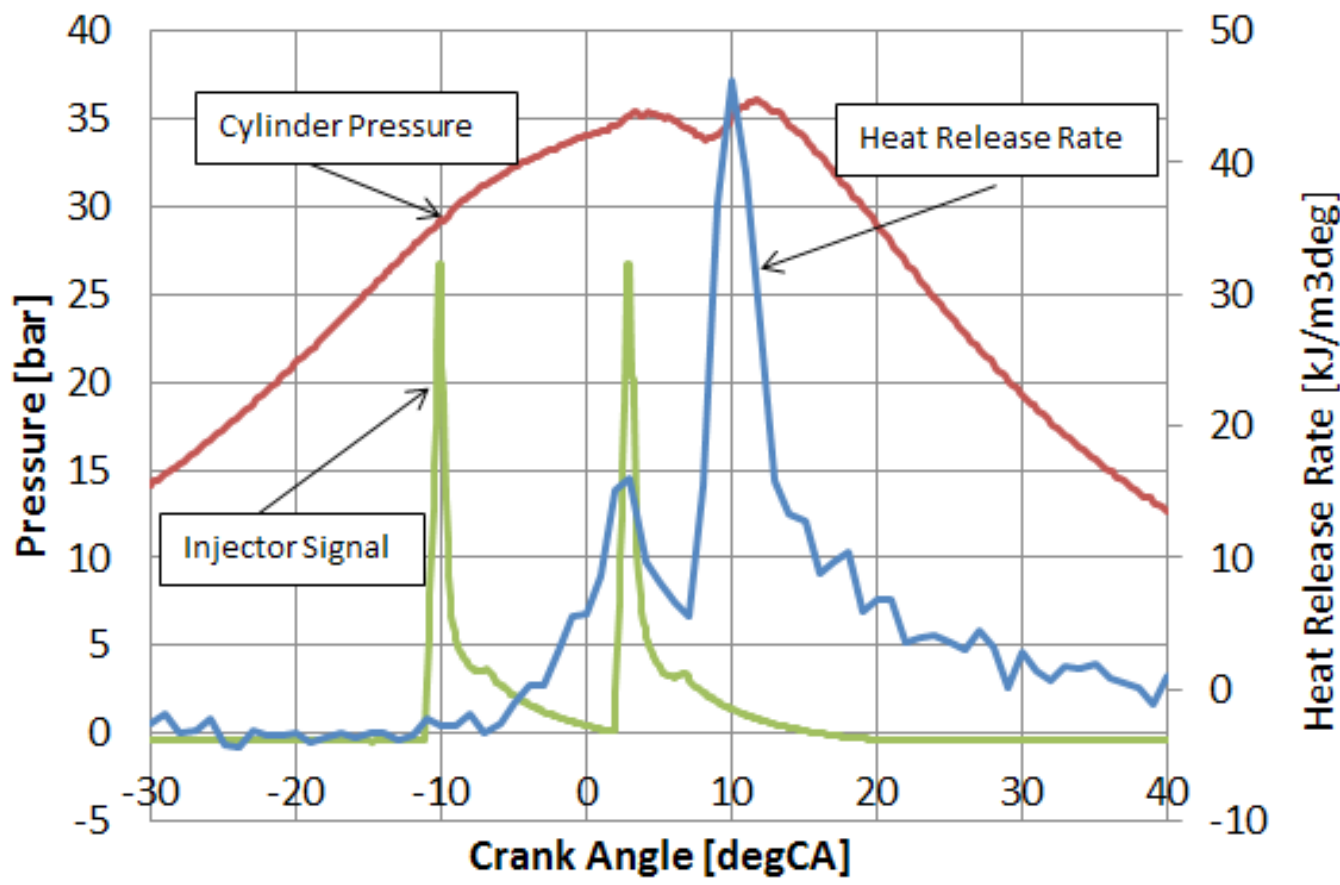

Figure 4: Measured in cylinder pressure, heat release rate and injection signal

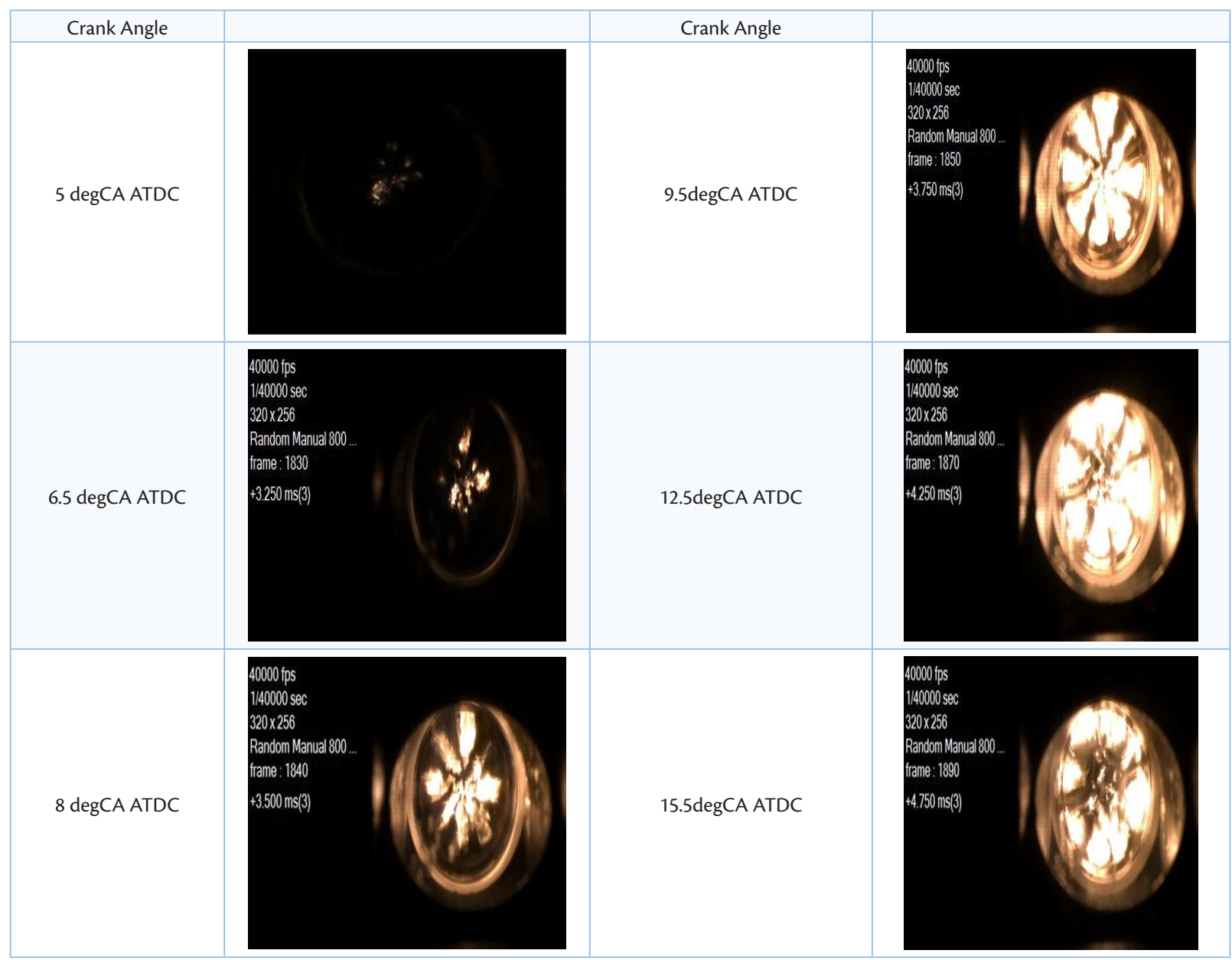

Figure 5: Flame propagation of the combustion chamber 


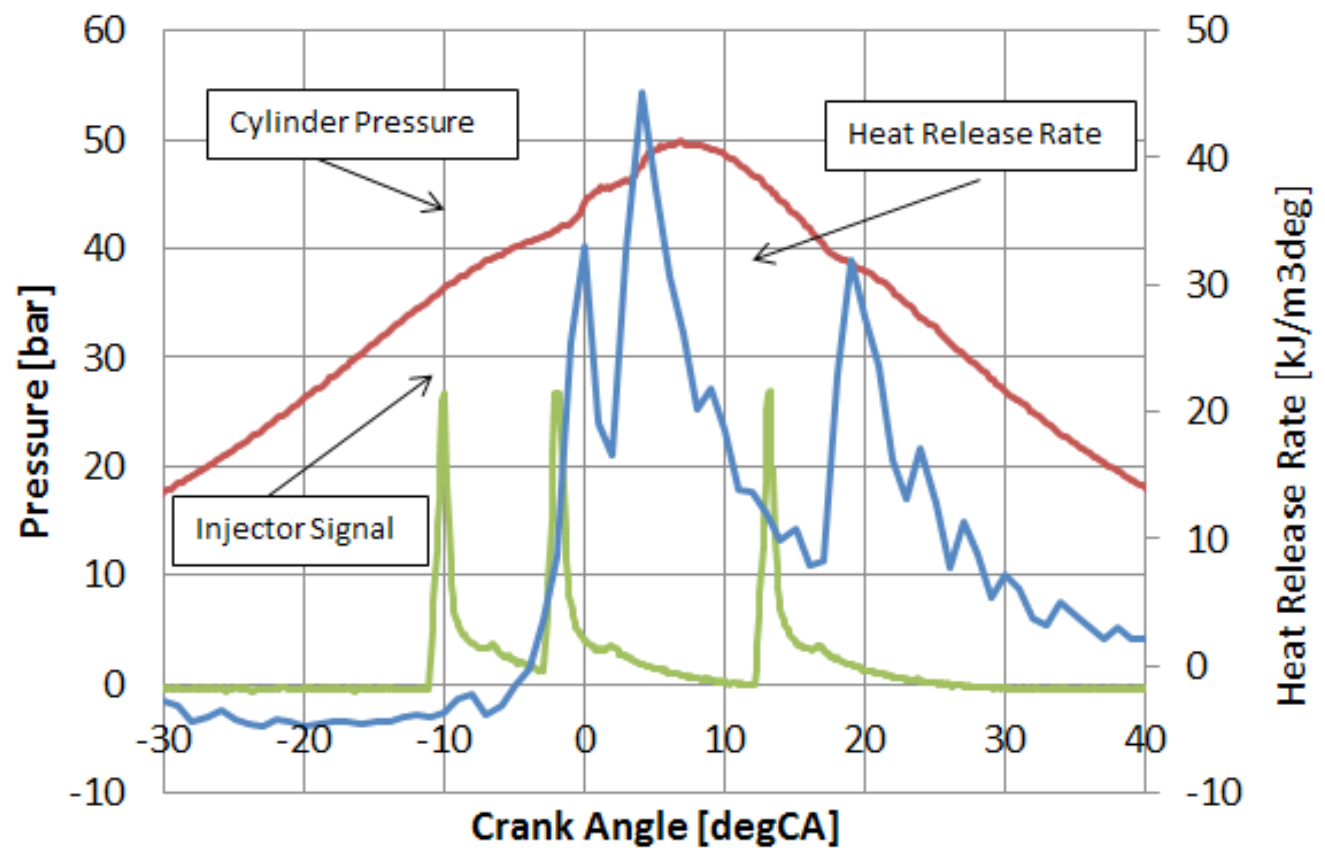

Figure 6: Measured in cylinder pressure, heat release rate and injection signal

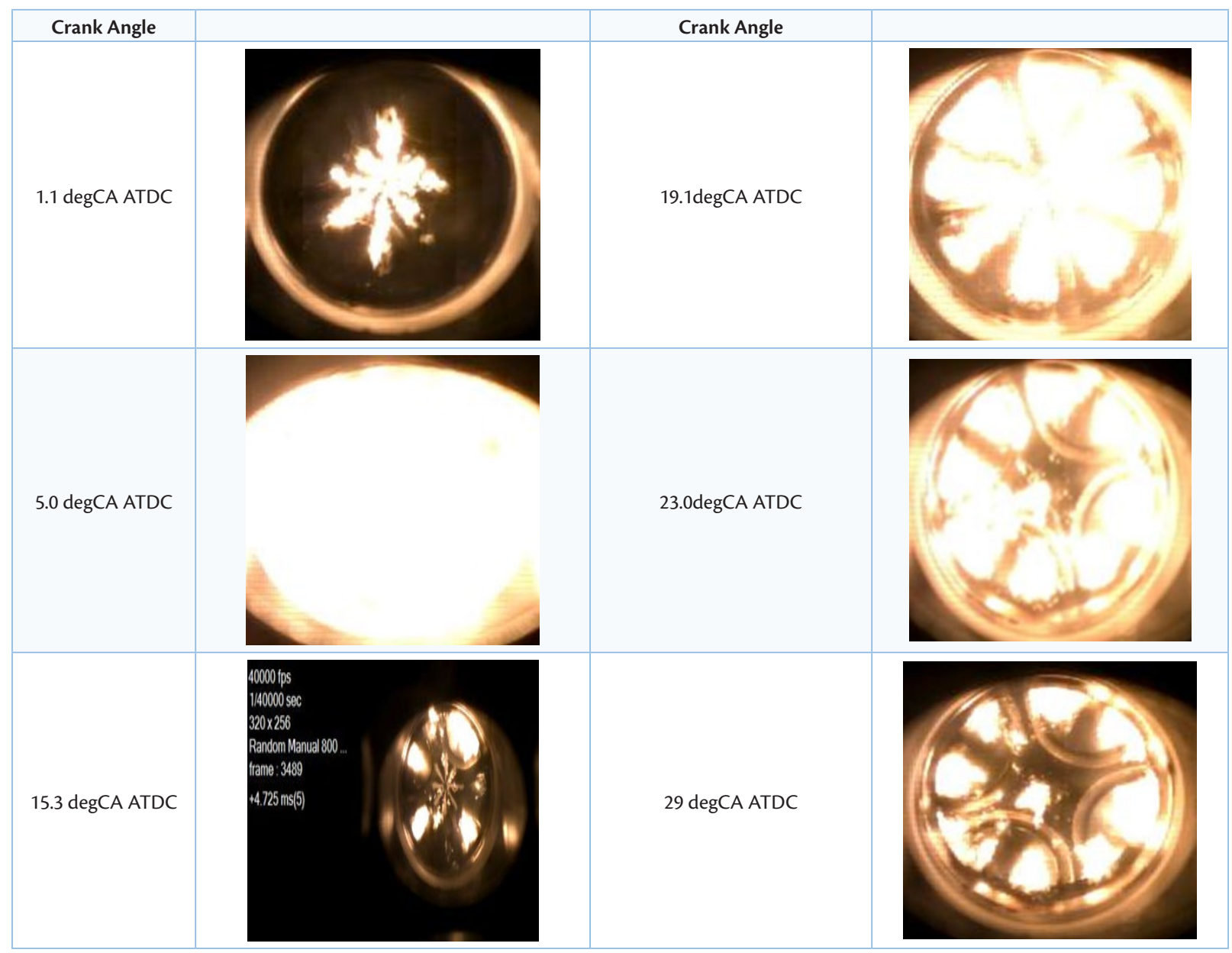

Figure 7: Flame propagation of the combustion chamber 


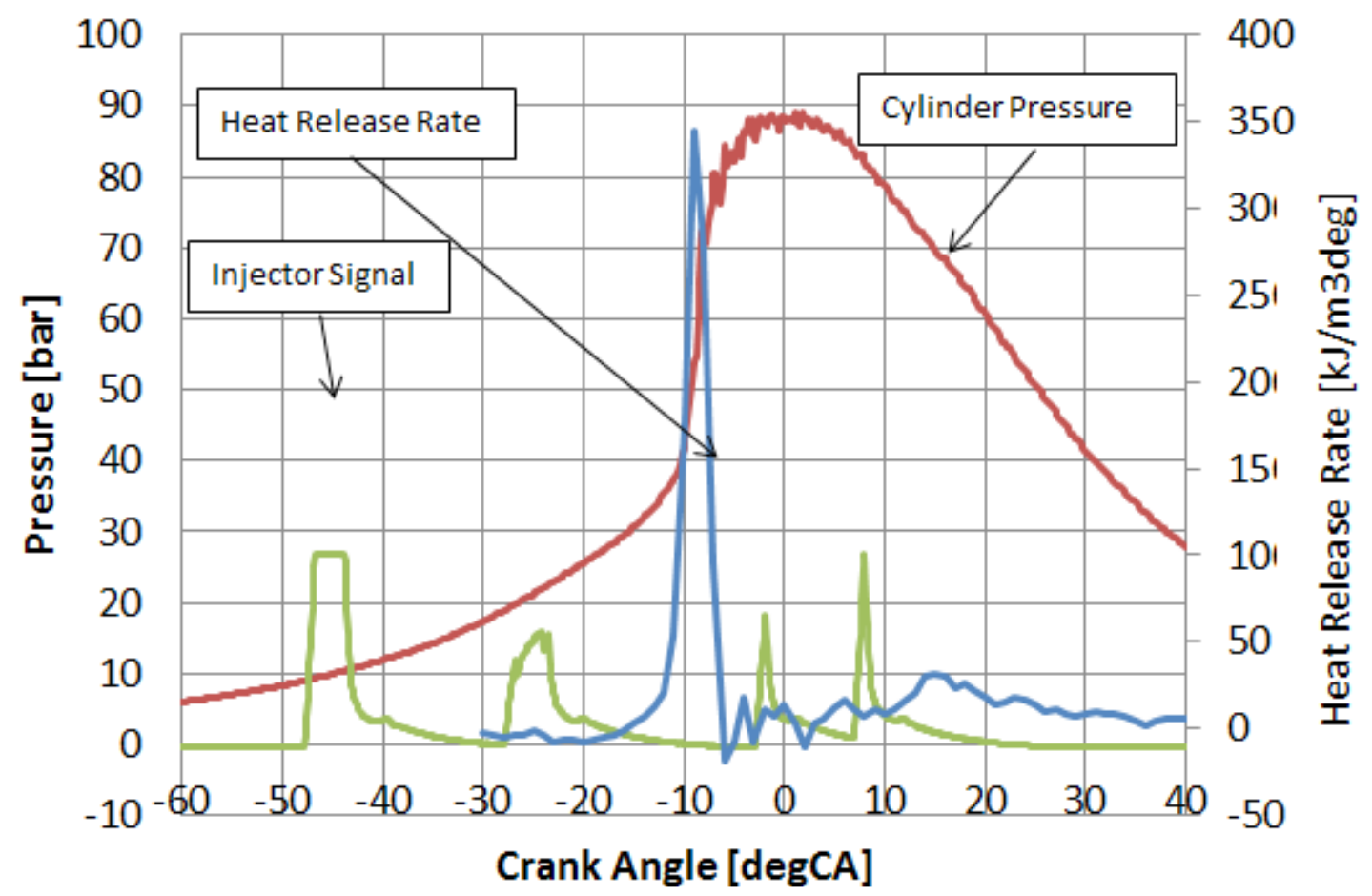

Figure 8: Measured in cylinder pressure, heat release rate and injection signal

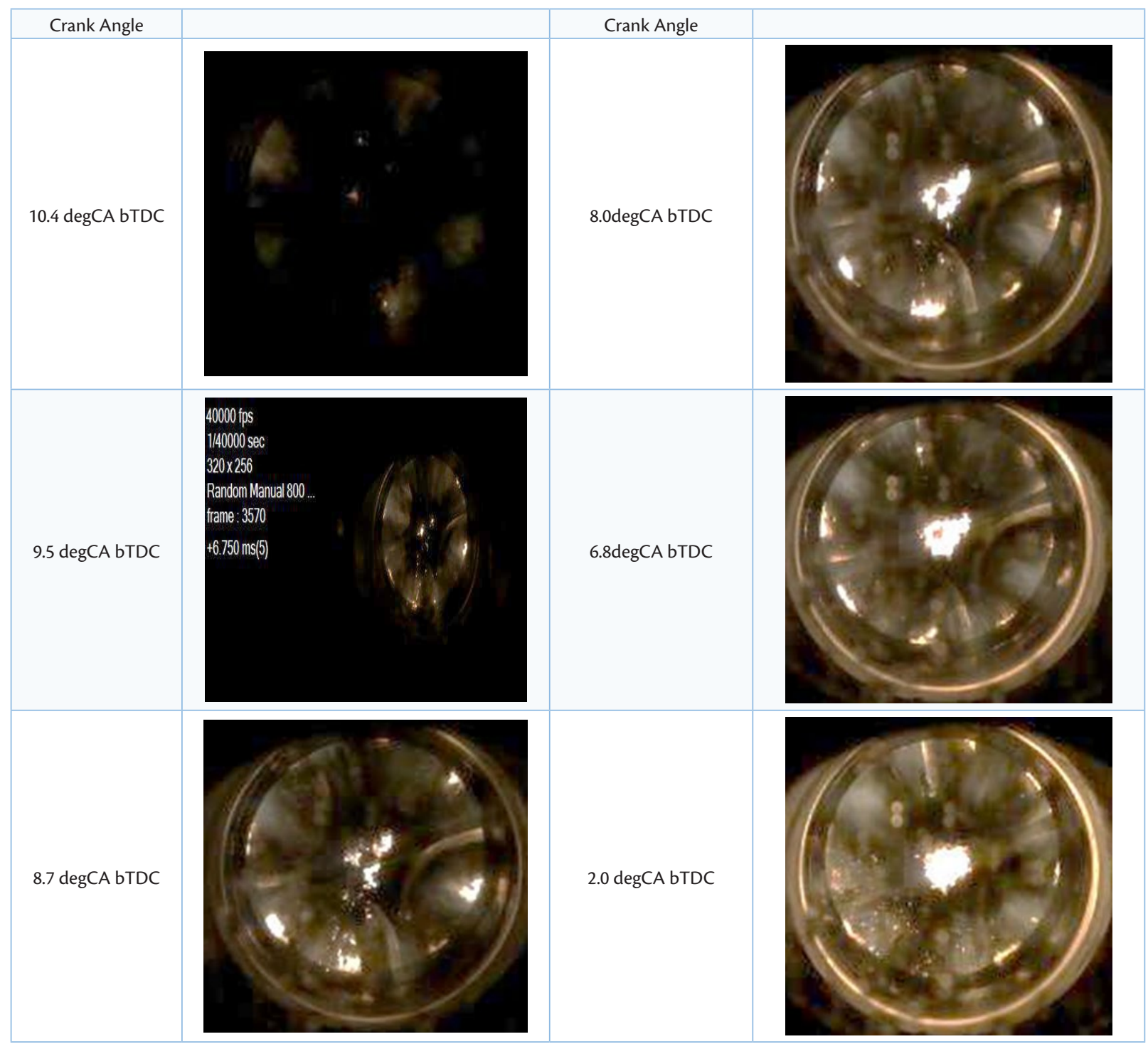

Figure 9: Flame propagation of the combustion chamber 
BTDC. Second pilot injection contributes to combustion at 5 degCA ATD and main injection starts to ignite at $17 \mathrm{deg}$ ATDC. Operating conditions are shown in Table 4 below.

Table 4 Engine Operation on Diesel Cycle

\begin{tabular}{|c|c|}
\hline Models & $\begin{array}{c}\text { Intake Manifold } \\
\text { Pressure }\end{array}$ \\
\hline Engine Speed [rpm] & 1100 \\
\hline Injected Fuel [mg/stroke] & 45 \\
\hline Pilot1 injection ratio [\%] & 33 \\
\hline Pilot2 injection ratio [\%] & 33 \\
\hline Rail pressure [bar] & 800 \\
\hline
\end{tabular}

In two piloted injection strategy, spray penetration length and the flame lift-off length can easily be seen. It is important for further correlation study of the combustion and spray simulations. As it is seen in the Figure 7, ignition starts around the fuel injector due to the closed pilot injections. Moreover, at $1.3 \mathrm{deg}$. CA main injector spray profile is observed. In addition, at $29 \mathrm{deg}$. CA, a small flame occurs near the fuel injector on the injector closing event. It is due to low fuel spray velocity and combustion takes place near the injector region.

\subsection{Partially Premixed Combustion Diesel Fuel}

Partially premixed combustion is an alternative way to reduce the $\mathrm{NO}_{\mathrm{x}}$ and soot emissions of the conventional diesel combustion event.[7] The idea of the partially premixed combustion is to inject the fuel far from the ignition limits that on the low temperature and pressure conditions of the cycle. As a result, fuel is preliminary mixed with air and starts to combust both assisted with main diesel injection near top dead center region or self-ignite over infinite regions near TDC. Premixed injection promotes the mixing which contributes the low soot regions to avoid local fuel rich regions. In this strategy, combustion is free from the local fuel rich regions. Therefore, temperature increase is limited resulting low $\mathrm{NO}_{x}$ production.

Partially premixed combustion can be initiated by using very early injection timing. In this work, a pilot injection is performed at $48 \mathrm{deg}$. CA BTDC and a second pilot at 28 deg. CA BTDC. Operating conditions are shown in Table 5 below.

Table 5 Engine Operation on Diesel Cycle

\begin{tabular}{|c|c|}
\hline \multicolumn{1}{|c|}{ Mable 5 Engine Operation on Diesel Cycle } \\
\hline Engine Speed [rpm] & $\begin{array}{c}\text { Intake Manifold } \\
\text { Pressure }\end{array}$ \\
\hline Injected Fuel [mg/stroke] & 1100 \\
\hline Pilot1 injection ratio [\%] & 45 \\
\hline Pilot2 injection ratio [\%] & 40 \\
\hline Main injection ratio [\%] & 30 \\
\hline Post injection ratio [\%] & 15 \\
\hline Rail pressure [bar] & 25 \\
\hline
\end{tabular}

Pressure rise rate is so steep for premixed combustion shown in Figure 8.

Moreover, in order to protect the engine, two post injections are used to combust the mixture in case of misfire conditions. Premixed combustion starts near liner region at $\sim 10$ deg. CA BTDC. Flame is not propagated like conventional diesel and suddenly ignites uniformly all over chamber. It is also observed that, the two post injections combusts near the injector zone. Light intensity is lower and flame is more uniform than the conventional diesel combustion. Combustion visualization results are shown in Figure 9 below.

\section{CONCLUSION}

Combustion visualization of conventional non-premixed, diffusion controlled and partially premixed combustion is performed. Considering, closed coupled pilot injection investigation, main injection combustion starts near injector region and a smoot heat release curve can be obtained. In the far pilot injection strategy, flame propagation is not attached to the pilot flame. This brings a light source of visualization of spray penetration length and flame lift-off length. Ignition delay of combustion, similar spray pattern preparation and flame propagation homogeneity the conventional diesel combustion is important to have good mixing properties of fuel and air. This can increase air utilization of the engine and thermal efficiency.

Secondly, in partially premixed combustion case, combustion occurs immediately and more homogenous on the combustion chamber and very rapid heat release rate production is observed. This can bring a low NOx and soot strategy due to homogenous combustion. It will be an alternative way to have better efficiency low emission engine operations.

\section{ACKNOWLEDGEMENTS}

Development and manufacturing activities of optical single cylinder engine was financially supported by TUBITAK TEYDEB within the Project Number:3120879. The optical engine experiments were performed on Ford Otosan İnönü Test Plan Centre. We would like to thank you for our colloquies of test center for helping us on engine installation and operation.

\section{REFERENCES}

[1] Weissback M. et all. (2003) "Alternative Combustion - An Approach for Future HSDI Diesel Engines", MTZ Worldwide, Vol. 64, No. 9, pp. $17-20$

[2] Pickett L. M. And Siebers D. L., (2004) "Non-sooting, low flame temperature mixing-controlled DI combustion", SAE Paper, 200401-1399.

[3] Larsson, A., (1999) "Optical Studies in a DI Diesel Engine," SAE Technical Paper 1999-01-3650, doi:10.4271/1999-01-3650.

[4] Schulz C., (2009) "Optical diagnostics in diesel combustion engines", Advanced Direct Injection Combustion Engine Technologies and Development: Diesel Engines, Zhao, H. (ed), pp 617-643

[5] Musculus, Mark P. B., (2006) "Multiple simultaneous optical diagnostics imaging of early injection low-temperature combustion in a heavy-duty diesel engine", SAE Technical Paper 2006-01-0079

[6] Kook, Sanghoon; Bae, Choongsik; Miles, Paul C. ; Choi, Dae ; Pickett, Lyle M., (2005) "The influence of charge dilution and injection timing on low-temperature dieselcombustion and emissions", SAE Technical Paper 2005-01-3837 
[7] Hanson, R.M., Splitter, D.A., Kokjohn, S.L., and Reitz, R. D., (2010) "An Experimental Investigation of Fuel Reactivity Controlled PCCI Combustion in a Heavy-Duty Engine," SAE Technical Paper 201001-0864 